\title{
Impact of brackets on smile esthetics: Laypersons and orthodontists perception
}

\author{
Seandra Cordeiro de Oliveira', Rachel D'Aurea Furquim² ${ }^{2}$ Adilson Luiz Ramos ${ }^{3}$
}

Objective: This study evaluated the influence of orthodontic appliances on smile esthetics assessed by lay adolescents, lay adults and orthodontists. Methods: A facial photograph of a smiling young woman was used under the following conditions: With metal orthodontic brackets ligated by different elastic ligature colors (green, red and gray), with ceramic bracket brackets (transparent elastic ligature) and without brackets, totaling five 15 x $20 \mathrm{~cm}$ pictures. For the photograph assessment, 16 lay adolescents, 16 lay adults and 16 orthodontists were randomly selected. The photographs were randomly arranged in an album, followed by a visual analog scale (VAS) for the scores registration. Scores in both evaluations of each group of evaluators (adolescents, adults and orthodontists) were submitted to error analysis by WILCOXON test and multiple comparison among groups performed by Kruskal - Wallis at 5\% significance. Results: Orthodontists, adults and adolescents agreed in their opinions, although the orthodontists gave lower scores in their assessments. It could be observed that ceramic brackets were more acceptable concerning the smile esthetics, whereas the metal brackets received the lowest scores. Conclusion: Orthodontists, adults and even adolescents seem to prefer esthetic solutions during orthodontic treatment.

Keywords: Esthetics. Dental. Visual perception. Orthodontic brackets.

Objetivo: esse estudo analisou a influência dos aparelhos ortodônticos na estética do sorriso em avaliação por adolescentes, adultos e ortodontistas. Métodos: foram utilizadas fotografias faciais do sorriso de uma jovem mulher, usando-se as seguintes combinações: aparelho ortodôntico de metal com ligaduras de diferentes cores (verde, vermelho e cinza); aparelho ortodôntico cerâmico (ligadura transparente); e sem aparelho - resultando em cinco fotografias de 15x20cm. Para a avaliação das fotografias, 16 adolescentes leigos, 16 adultos leigos e 16 ortodontistas foram selecionados de forma randômica. As fotografias foram aleatoriamente organizadas em um álbum, acompanhadas de uma escala visual analógica (EVA) para o registro das notas. As notas das duas avaliações de cada grupo (adolescentes, adultos e ortodontistas) foram submetidas à análise de erro (teste pareado de Wilcoxon) e comparação múltipla de grupos pelo teste de Kruskal-Wallis com significância de 5\%. Resultados: ortodontistas, adultos e adolescentes concordaram em suas opiniões, porém, os ortodontistas deram notas menores em suas avaliações. Pôde ser observado que os braquetes cerâmicos foram mais aceitos, considerando-se a estética do sorriso, uma vez que os braquetes metálicos tiveram as menores notas. Conclusão: ortodontistas, adultos e adolescentes parecem preferir soluções estéticas durante o tratamento ortodôntico.

Palavras-chave: Percepção visual. Braquetes ortodônticos. Estética dentária.

${ }^{1}$ Specialist in Orthodontics, Maringaense Association of Dentistry.

${ }^{2}$ MSc student in Integrated Dentistry, UEM.

${ }^{3}$ Associate Professor, Dentistry Department, UEM. Coodinator od the PostGraduation course in Integrated Dentistry, UEM.

${ }^{4}$ Professor of Orthodontics. UEM.
How to cite this article: Oliveira SC, Furquim RD, Ramos AL. Impact of brackets on smile esthetics: Laypersons and orthodontists perception. Dental Press J Orthod. 2012 Sept-Oct;17(5):64-70.

Submitted: April 09, 2010 - Revised and accepted: June 05, 2012

» The authors report no commercial, proprietary or financial interest in the products or companies described in this article.

" Patients displayed in this article previously approved the use of their facial and intraoral photographs.

Contact address: Rachel D’Aurea Furquim

Rua Carlos Chagas, 247 - Zona 5 - Zip code: 87.015-240 - Maringá/PR

E-mail: rachelfurquim@odontoestetica.com.br 


\section{INTRODUCTION}

One of the main reasons that motivate patients to start an orthodontic treatment is the esthetic factor, ${ }^{1-3}$ as well as joint dysfunction and improvement of dental health as a whole. ${ }^{4}$ Patients that look for orthodontic treatment present a more critical self-perception, both of the face, as well as the teeth, than those who do not look for treatment. This fact suggests that patients that look for orthodontic treatment, in general, are more demanding about esthetic looks. ${ }^{5}$

The smile can have an important influence once that faces with better looking smiles are considered to be more acceptable esthetically ${ }^{6,7}$ and it can be associated with psychological characteristics. ${ }^{8,9}$

Even considering that beauty is quite subjective and is associated with many factors, the professional has the responsibility to capture the patients' desires that is the main goal of treatment. Once the patient starts an orthodontic treatment for esthetic reasons, it is consistent to assert that during the treatment he is also concerned about his esthetics. The use of orthodontic brackets can harm the appearance, even if it is temporary.

Long term treatment and non-esthetic appearance of metal brackets are the main reasons for adult patients declining to start orthodontic treatment ${ }^{4}$. Facing that, the industry for dental materials has been looking to offer alternatives so the treatment becomes more esthetic, developing specific treatment techniques and technology, such as lingual orthodontics, transparent aligners, and use of esthetic brackets. ${ }^{10}$ A recent study concluded that adult patients would pay more to use alternative appliances and ceramic brackets, once they were considered to be more acceptable and attractive than the metallic conventional ones. ${ }^{11}$

A German survey shows that $97 \%$ of the patients (comprised mainly by females) wishes to have their malocclusions corrected for esthetic reasons, but $62 \%$ rejected treatment with a visible appliance. ${ }^{12}$ In Sweden, a survey showed that $67 \%$ would probably wear visible brackets if needed. However, based on appearance of the brackets alone, 33\% of the adults would be unwilling to wear visible brackets if needed. The same group additionally responded that $84 \%$ would probably or definitely treated with visible brackets during adolescence if needed. ${ }^{13}$ These responses suggest a dichotomy between acceptability of orthodontic appliance for adolescents and adults.

However, to date no studies have been published on the real impact of this kind of orthodontic accessories on smile esthetics perceived by adolescents in comparison with adults or orthodontists, even with metal brackets, being used in a larger scale in orthodontic clinics. A previous investigation ${ }^{14}$ examining 18 years old youngsters found that orthodontic appliance attractiveness varies significantly by the following hierarchy of appliance types: Alternative appliances > ceramic appliances > all stainless steel and self-ligating appliances. ${ }^{14}$ Recently, the impact of orthodontic brackets on the esthetics of the face when smiling, with and without premolar extraction was evaluated by lay adults and orthodontists. This investigation concluded that metal orthodontic brackets did not affect facial esthetics. On the other hand, they found that ceramic brackets were significantly less pleasant to lays. To orthodontists, ceramic brackets had no negative influence on facial esthetics. The authors also concluded that perception of lay adults and orthodontists was different. ${ }^{15}$

Facing the lack of studies about the impact of orthodontic brackets on smile esthetics, particularly among adolescents, it is difficult for orthodontists to inform their patients which brackets to choose based on scientific evidence. This lack of information also becomes relevant when considering the high investments done by industries of dental materials in an effort to develop and commercialize orthodontic brackets more imperceptible to human eyes.

\section{MATERIAL AND METHODS}

A female volunteer with a pleasant smile was photographed in the frontal aspect, with a CANON 30 D 8.0 megapixel camera, with a $100 \mathrm{~mm}$ macro lens in a distance of one meter. The metal orthodontic brackets (Abzil/3M-Brazil) and the ceramic ones (Inspire - Ice - ORMCO, California, - United States) were temporarily bonded (with easy removal and only to perform the pictures) on the volunteer's upper teeth with a cheek retractor 
and no acid etching. Adhesive and Transbond XT composite (3M Unitek, California, EUA) were used and cured for 10 seconds to this sample of brackets. A stainless steel arch 0.018-in was used as reference to level bracket position and fixed with ligatures (Morelli, São Paulo, Brazil). Photos of volunteer smiling were obtained in three conditions: Without brackets, with ceramic brackets ligated by transparent elastic ligatures and with metal brackets ligated by different ligature colors (green, red and gray).

One of the photographs in which the patient is smiling was selected as the matrix, which was used as reference to obtain smile standardization. Close up photographs were taken with metal and ceramic orthodontic brackets, which were transferred to the matrix photo, with a digital simulation using the software Adobe Photoshop CS2.

The teeth and orthodontic bracket images of the other photos were transferred to the matrix photo in order to maintain the same relation between lips and teeth in the smile and the same head positioning at all result photos, so that the only difference between the simulated photos was the orthodontic brackets.

The photos were: A matrix photograph (Fig 1) and four manipulated photographs with images of all kinds of brackets and elastic ligature used (Fig 2).

Color prints with picture quality in size $15 \times 20 \mathrm{~cm}$ were obtained and randomly grouped in an album. The evaluators were randomly selected and distributed in the following groups: 16 adolescents between 13 and 17 years old ( 8 males and 8 females), 16 graduate adults between 25 and 50 years old (8 males and 8 females) and 16 orthodontists, aged 26-48 years old ( 8 males and 8 females).

Each evaluator received an album with five photos, an instruction sheet and five evaluation sheets with visual analogue scales (VAS) ${ }^{16}$ with $10 \mathrm{~cm}$ each and a sheet to collect data (age, schooling level and address). On the left end of the scale was written "Very unpleasant" and on the right end "Very pleasant" (Fig 3).

The raters were instructed not to compare the smiles of the album. They had around 20 seconds to evaluate each photo. The VAS scale sheet was fulfilled in the researcher presence, without any interference. After two weeks a second evaluation was performed similar to the first one, in order to evaluate the error of method.

\section{Statistical analysis}

Scores in both evaluations of each group (adolescents, adults and orthodontists) were submitted to

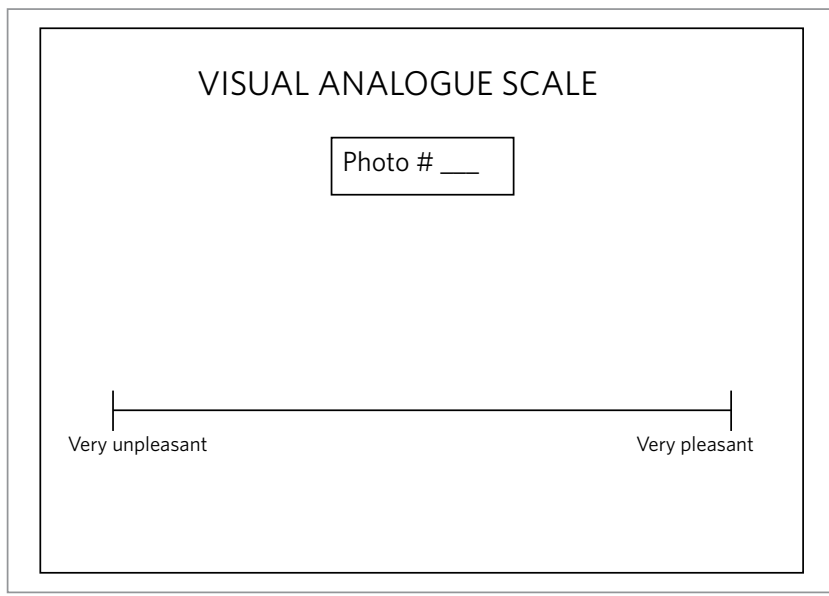

Figure 1 - Visual Analogue Scale.

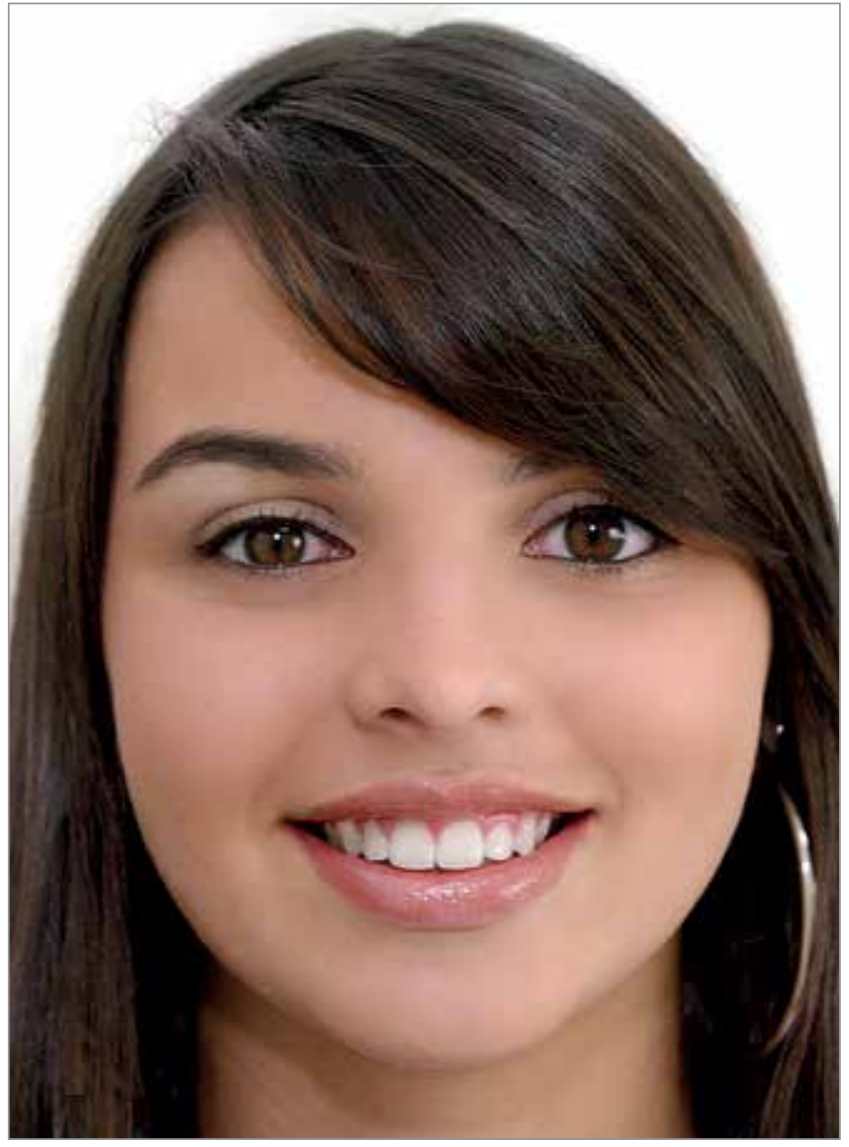

Figure 2 - Smile without brackets (NB). 

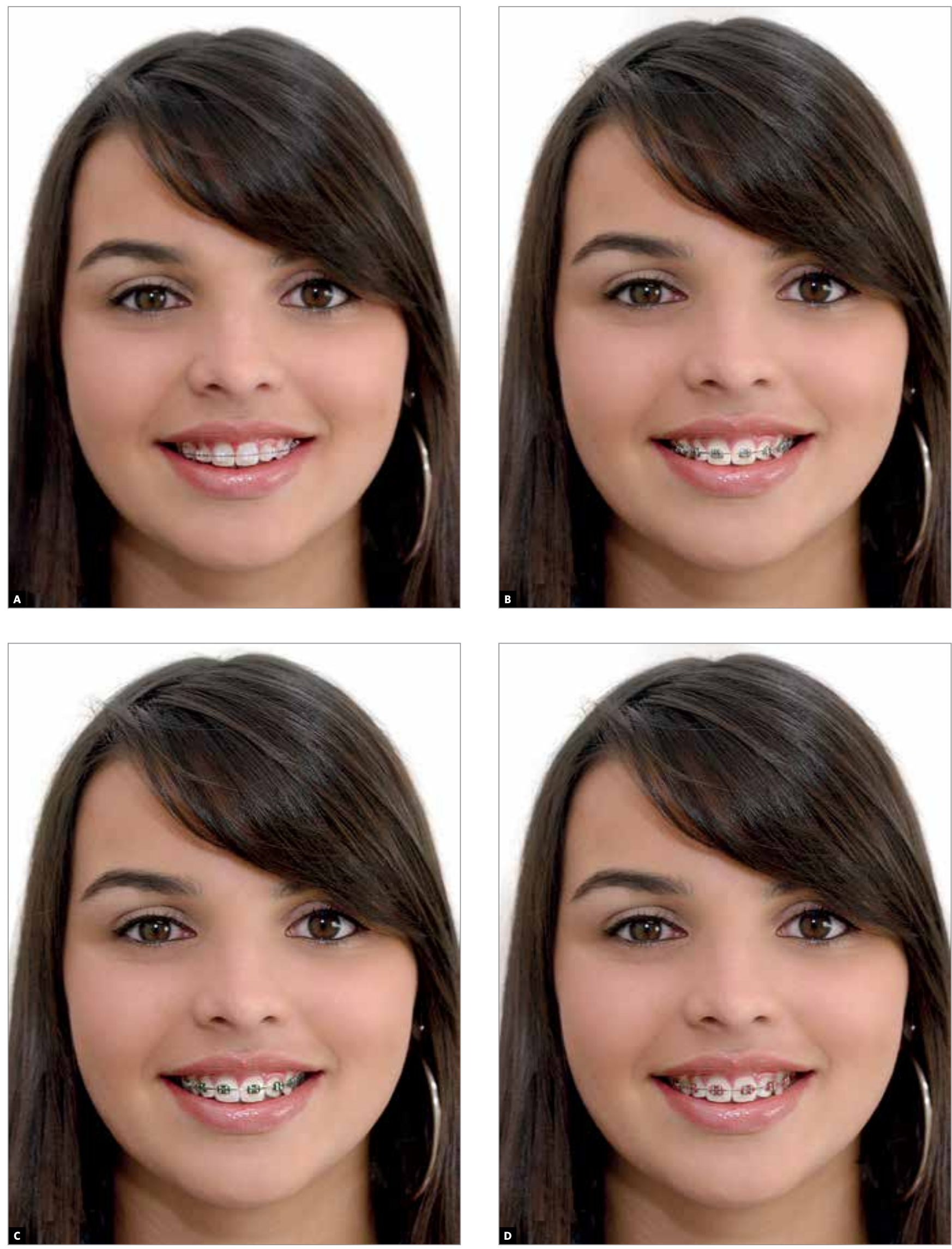

Figure 3 - A) Smile with ceramic brackets (CB). B) Metal brackets + gray ligatures $(M B+G Y)$. C) Metal brackets + green ligatures $(M B+G N)$. D) Metal brackets + red ligatures $(M B+R)$. 
Table 1 - Descriptive data of the scores obtained by VAS.

\begin{tabular}{|c|c|c|c|c|c|c|}
\hline \multirow{2}{*}{ Group } & \multirow{2}{*}{ Treatment } & \multirow{2}{*}{ Mean } & \multirow{2}{*}{$\begin{array}{l}\text { Standard } \\
\text { Deviation }\end{array}$} & \multirow{2}{*}{$\mathbf{n}$} & \multicolumn{2}{|c|}{$95 \%$ confidence interval } \\
\hline & & & & & Lower Limit & Upper Limit \\
\hline \multirow{5}{*}{ Adolescents } & $\mathrm{CB}$ & 70.47 & 21.41 & 32 & 62.750 & 78.187 \\
\hline & $M B+G N$ & 55.81 & 19.98 & 32 & 48.610 & 63.015 \\
\hline & $M B+R$ & 61.56 & 14.84 & 32 & 56.213 & 66.912 \\
\hline & $M B+G Y$ & 60.28 & 17.26 & 32 & 54.060 & 66.503 \\
\hline & NB & 74.81 & 12.79 & 32 & 70.202 & 79.423 \\
\hline \multirow{5}{*}{ Adults } & $\mathrm{CB}$ & 80.56 & 13.46 & 32 & 75.709 & 85.416 \\
\hline & $\mathrm{MB}+\mathrm{GN}$ & 64.72 & 21.07 & 32 & 57.123 & 72.314 \\
\hline & $M B+R$ & 65.88 & 18.38 & 32 & 59.247 & 72.503 \\
\hline & $M B+G Y$ & 66.72 & 19.24 & 32 & 59.782 & 73.655 \\
\hline & NB & 78.63 & 15.01 & 32 & 73.214 & 84.036 \\
\hline \multirow{5}{*}{ Orthodontists } & $\mathrm{CB}$ & 70.34 & 16.30 & 32 & 64.468 & 76.219 \\
\hline & $M B+G N$ & 50.72 & 19.21 & 32 & 43.793 & 57.645 \\
\hline & $M B+R$ & 56.09 & 17.07 & 32 & 49.939 & 62.248 \\
\hline & $M B+G Y$ & 57.06 & 20.29 & 32 & 49.748 & 64.377 \\
\hline & NM & 66.50 & 19.84 & 32 & 59.348 & 73.652 \\
\hline
\end{tabular}

an error analysis using of Wilcoxon signed-rank test. Multiple comparisons among groups were performed using Kruskal-Wallis test. All the statistics were performed using two-tailed distribution at $\mathrm{p}>0.05$.

\section{RESULTS}

Table 1 presents intra-group comparisons. It can be observed that all groups presented similar behaviors, scoring smiles with ceramic brackets as well as smiles without brackets as more esthetical.

The averages were tested between genders and presented on table 2 . There was no significant difference between genders, except on the $\mathrm{MB}+\mathrm{GN}$ combination (metal bracket+ green ligature), where the female gender presented a smaller average in comparison to the male evaluators $(\mathrm{p}<0.05)$.

The intergroup analysis showed that orthodontists presented higher esthetic levels especially to the combinations $\mathrm{MB}+\mathrm{R}, \mathrm{MB}+\mathrm{GN}, \mathrm{NB}$. For the $\mathrm{CB}$ and $\mathrm{CB}+\mathrm{GY}$ the lay adolescent group showed to be as demanding as orthodontists. The lay adult group showed to be less demanding than the other groups for all proposed combinations (Table 3, Fig 4), marking higher scores in general.

Figure 4 illustrates the scores behavior of all groups of evaluators. A clear similarity was found on the behavior of the curves, especially differing the lay adult's scores, as well as the best grades for the smile without brackets or with ceramic brackets.
Table 2 - Multiple comparison (Kruskal-Wallis) to the average comparison of the two genders for each combination.

\begin{tabular}{cccccc}
\multirow{2}{*}{ Group } & \multicolumn{5}{c}{ Average Score Treatment } \\
\cline { 2 - 6 } & $\mathbf{C B}$ & $\mathbf{M B + G N}$ & $\mathbf{M B + R}$ & $\mathbf{M B + G Y}$ & NB \\
\hline Male & $74.25^{\mathrm{a}}$ & $61.29^{\mathrm{a}}$ & $64.08^{\mathrm{a}}$ & $62.35^{\mathrm{a}}$ & $73.48^{\mathrm{a}}$ \\
Female & $73.33^{\mathrm{a}}$ & $52.87^{\mathrm{b}}$ & $58.27^{\mathrm{a}}$ & $60.35^{\mathrm{a}}$ & $73.14^{\mathrm{a}}$ \\
\hline
\end{tabular}

* Averages on the columns with different letters are statistically different on the $5 \%$ level of significance ( $p$ value $<0.05$ ).

Table 3 - Multiple comparison (Kruskal Wallis) between score averages for each group of evaluators.

\begin{tabular}{cccccc}
\multirow{2}{*}{ Group } & \multicolumn{5}{c}{ Average score } \\
\cline { 2 - 6 } & $\mathbf{C B}$ & $\mathbf{M B + G N}$ & $\mathbf{M B + R}$ & $\mathbf{M B + G Y}$ & NB \\
\hline Adolescents & $70.47^{\mathrm{a}}$ & $55.81^{\mathrm{a}}$ & $61.56^{\mathrm{a}}$ & $60.28^{\mathrm{a}}$ & $74.81^{\mathrm{a}}$ \\
Adults & $80.56^{\mathrm{b}}$ & $64.72^{\mathrm{b}}$ & $65.88^{\mathrm{a}}$ & $66.72^{\mathrm{a}}$ & $78.63^{\mathrm{a}}$ \\
Orthodontists & $70.34^{\mathrm{a}}$ & $50.72^{\mathrm{a}}$ & $56.09^{\mathrm{b}}$ & $57.06^{\mathrm{b}}$ & $66.50^{\mathrm{b}}$ \\
\hline
\end{tabular}

${ }^{*}$ Averages on the columns with different letters are statistically different on the $5 \%$ level of significance ( $p$ value $<0.05$ ).

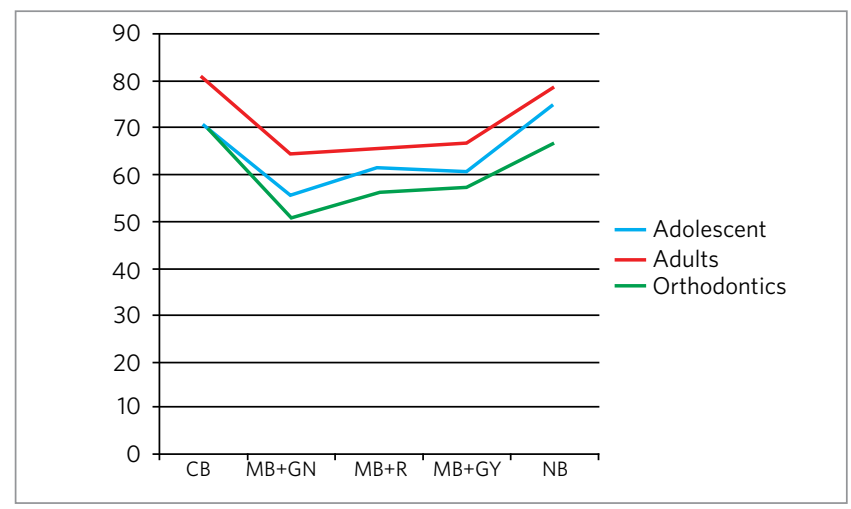

Figure 4 - Average scores for the three evaluators groups. 


\section{DISCUSSION}

The adult demand for orthodontic treatment increased, inn most cases for esthetic reasons., ${ }^{3,10}$ Because of this, it would be reasonable to assume that patients, especially adults, would not only be concerned about the esthetics in the end of the treatment, but also during the whole process. Although this affirmation is confirmed for adults, ${ }^{12-15}$ no study had been conducted on adolescents' attractiveness perception when using brackets, maybe because it is presumed that adolescents are used to a "metallic smile".

Our results showed that adolescents recorded similar scores between the smiles with or without ceramic brackets. On the other hand, smiles with metal brackets, regardless of the ligature color used, were considered less pleasant. In fact, adolescents were more demanding in esthetic reasons than the adult evaluator group, contradicting the idea that adolescents tend to feel better with a "metallic smile". This can suggest that the esthetic requirement is very updated, even in young patients and not only restricted to the adult public. Maybe this is due to the influence of the media, the increased number of patients under orthodontic treatment, or by cultural and socio-economic aspects. . $^{3,10,15}$

Considering that orthodontic treatment requires time to be accomplished, it would be acceptable that, even adolescents would choose brackets that interfere the minimum possible on their appearance, being discrete or even non perceivable. ${ }^{10,11}$ Thus, orthodontists should concern about the population requests. Although clear aligners, lingual and ceramic brackets are most commonly used in adults, ${ }^{12-15}$ we can expect an increasing demand for these esthetic options among adolescents.

It is appropriate to emphasize that metal brackets ligated by green elastomers, which were the less scored, presented an average of $55.81 \mathrm{~mm}$ in VAS scale by adolescents, $64.72 \mathrm{~mm}$ by adults and $50.72 \mathrm{~mm}$ by orthodontist (Table 3 ). Thus, it can be considered that the metal brackets were not negatively scored (as VAS measurements were above $50 \mathrm{~mm}$ ), but had a higher impact on the smile esthetics than the ceramic brackets. Although it is a value and an appearance question for patients. ${ }^{11,14}$ the appliances should be selected on the efficiency basis. In fact, less attractive appliances are most commonly used in orthodontic practice..$^{21}$ It was pointed that ceramic brackets could be less efficient than metallic in terms of fracture resistance and sliding quality. ${ }^{11,14}$ Furthermore, to date, it was reported that clear aligners still need improvements to achieve clinical performance compared to conventional brackets. ${ }^{22}$

Although there was homogeneity in respect to smile esthetics, the orthodontic group showed to be more demanding for all proposed combinations, with smaller scores in general. Other perception studies showed similar judgment behavior between orthodontists and lay people. ${ }^{17-20}$

Many studies have evaluated characteristics of both dental and facial esthetics, rating photographic records with a visual analog scale (VAS), which has been shown to be a valid method of assessing dental attractiveness., ${ }^{1,6,11,14,15,17-20,23}$ Two evaluations with two weeks interval in this study showed no significant differences in all groups. When genders of evaluators were compared, metallic brackets with green ligation were the only significant different measurement found in female group, who scored less attractive than males.

In this study, evaluators judged photographs of the whole face and not by limited dental frameworks of the smile. In this way smiles are evaluated as a part of the whole esthetics of the face. In photos with guidelines about the smile, there is overvaluing of certain characteristics of the smile in question, particularly negative characteristics. ${ }^{20}$ Despite of different evaluation methods, our results agree with Rosvall et $\mathrm{al}^{11}$ and Ziuchkovski et $\mathrm{al}^{14}$ where both orthodontists and lay people classified the devices in a hierarchy where the attractiveness decreased with increasing amount of metal present. In opposite, Berto et al ${ }^{15}$ found that lay people prefer metallic brackets than ceramic, however an extraction site was present in their photographs, which could affected perception.

It is suitable to say that in the present study all brackets were temporarily bonded, then photographed and lately removed. This way, they were not allowed to pass through the environmental 
conditions caused by time and the actual orthodontic treatment, which would be more significant, once they could change, mainly on the bracket/ transparent ligature, which could affect their esthetic perception. This fact suggests that more studies should be conducted with the objective of evaluating the perception of the esthetic of these devices, in long-term.

\section{CONCLUSIONS}

»Considering the esthetic aspect, smiles with metal brackets presented smaller scores than smiles without brackets and with ceramic brackets.

» Adolescents, adults and orthodontists showed similar perceptions on the evaluation of the impact of brackets on smile esthetics.

\section{REFERENCES}

1. Prahl-Andersen B, Boersma H, van der Linden FP, Moore AW. Perception of dentofacial morphology by laypersons, general dentists, and orthodontists. Am J Dent Assoc. 1979;98:209-12.

2. Giddon DB, Sconzo R, Kinchen JA, Evans CA. Quantitative comparison of computerized and animated profile preferences. Angle Orthod. 1996;66:441-8.

3. Reis $S A B, A$ brão J, Capelozza Filho L, Claro CAA. Análise facial subjetiva. Rev Dental Press Ortodon Ortop Facial. 2006;11(5):159-72.

4. Khan RS, Morrocks EN. A study of adult orthodontic patients and their treatment. Br J Orthod. 1991 Aug;18(3):183-94.

5. Varela M, Garcia-Camba JE. Impact of orthodontics on the psychologic profile adult patients: a prospective study. Am J Orthod Dentofacial Orthop. 1995 Aug;108(2):142-8.

6. Shaw WC, Rees G, Dawe M, Charles CR. The influence of dentofacial appearance on the attractiveness of young adults. Am J Orthod. 1985 Jan;87(1):21-6

7. York J, Holtzman J. Facial attractiveness and the aged. Spec Care Dentist. 1999 Mar-Apr;19(2):84-8.

8. Dong JK, Jin TH, Cho HW, Oh SC. The esthetics of the smile: a review of the recent studies. Int J Prosthodont. 1999 Jan-Feb;12(1):9-19.

9. van der Geld P, Oosterveld P, Van Heck G, Kuijpers-Jagtman AM. Smile attractiveness. Self-perception and influence on personality. Angle Orthod. 2007 Sep;77(5):759-65

10. Maltagliati LA, Feres R, Figueiredo MA, Siqueira DF. Braquetes estéticos: considerações clínicas. Rev Clín Ortodon Dental Press. 2006;5(3):75-81.

11. Rosvall MD, Fields HW, Ziuchkovski J, Rosenstiel SF, Johnston WM. Attractiveness, acceptability, and value of orthodontic appliances. Am J Orthod Dentofacial Orthop. 2009 Mar;135(3):276.e1-12; discussion 276-7.

12. Meier B, Wiemer KB, Miethke R. Invisalign-patient profiling. J Orofac Orthop. 2003 Sep;64(5):352-8
13. Bergström K, Halling A, Wilde B. Orthodontic care from the patients' perspective: perceptions of 27-year-olds. Eur J Orthod. 1998;20(3):319-29.

14. Ziuchkovski JP, Fields HW, Johnston W, Lindsey D. Assessment of perceived orthodontic appliance attractiveness. Am J Orthod Dentofacial Orthop. 2008 Apr;133(4 Suppl):S68-78

15. Berto PM, Lima CS, Lenza MA, Faber, J. Esthetic effect of orthodontics appliances on a smiling face with and without a missing maxillary first premolar. Am J Orthod Dentofacial Orthop. 2009 Apr;135(4 Suppl):S55-60.

16. Aitken RC. Measurement of feelings using visual analogue scale. Proc R Soc Med. 1969;62(10):989-93.

17. Anderson KM, Behrents RG, McKinney T, Buschang PH. Tooth shape preferences in an esthetic smile. Am J Orthod Dentofacial Orthop. 2005 Oct;128(4):458-65.

18. Parekh $\mathrm{S}$, Fields $\mathrm{H}$, Beck F, Rosenstiel $\mathrm{S}$. The acceptability of variations in smile arc and buccal corridor space. Orthod Craniofac Res. 2007 Feb;10(1):15-21.

19. Kokich VO, Kokich VG, Kiyak HA. Perceptions of dental professionals and laypersons to altered dental esthetics: asymmetric and symmetric situations. Am J Orthod Dentofacial Orthop. 2006 Aug;130(2):141-51.

20. Flores-Mir C, Silva E, Barriga MI, Lagravere MO, Major PW. Lay person's perception of smile aesthetic in dental and facial views. J Orthod. 2004 Sep;31(3):204-9; discussion 201

21. Keim RG, Gottlieb EL, Nelson AH, Vogels DS 3rd. 2002 JCO study of orthodontic diagnosis and treatment procedures. Part 1. Results and trends. J Clin Orthod. 2002 Oct;36(10):553-68

22. Djeu G, Shelton C, Maganzini A. Outcome assessment of Invisalign and traditional orthodontic treatment compared with the American Board of Orthodontics objective grading system. Am J Orthod Dentofacial Orthop. 2005 Sep;128(3):2928; discussion 298.

23. Howells DJ, Shaw WC. The validity and reliability of ratings of dental and facial attractiveness for epidemiologic use. Am J Orthod. 1985 Nov;88(5):402-8. 